\title{
Immune, Autonomic, and Endocrine Dysregulation in Autism and Ehlers-Danlos Syndrome/Hypermobility Spectrum Disorders Versus Unaffected Controls
}

\section{Emily L. CASANOVA, Julia L.SHARP², Stephen M. EDELSON ${ }^{3}$, Desmond P. KELLY', ${ }^{4}$, Estate M. SOKHADZE ${ }^{1}$, ManuelF. CASANOVA ${ }^{1,4}$}

\author{
${ }^{1}$ Department of Biomedical Sciences, University of South \\ Carolina School of Medicine Greenville, South Carolina, USA \\ ${ }^{2}$ Department of Statistics, Colorado State University, Fort Collins, \\ Colorado, USA \\ ${ }^{3}$ Autism Research Institute (ARI), San Diego, California, USA \\ ${ }^{4}$ Department of Pediatrics, Greenville Health System Children's \\ Hospital, Greenville, South Carolina, USA \\ Research Article
}

Background: A growing body of literature suggests etiological overlap between Ehlers-Danlos syndrome (EDS)/hypermobility spectrum disorders (HSD) and some cases of autism, although this relationship is poorly delineated. In addition, immune, autonomic, and endocrine dysregulation are reported in both conditions and may be relevant to their respective etiologies.

Aims: To study symptom overlap in these two comorbid spectrum conditions.

Methods and Procedures: We surveyed 702 adults aged 25+ years on a variety of EDS/HSD-related health topics, comparing individuals with EDS/HSD, autism, and unaffected controls.

Outcomes and Results: The autism group reported similar though less severe symptomology as the EDS/HSD group, especially in areas of immune/autonomic/endocrine dysregulation, connective tissue abnomalities (i.e., skin, bruising/bleeding), and chronic pain. EDS/HSD mothers with autistic children reported more immune symptoms than EDS/HSD mothers without, suggesting the matemal immune system could play a heritable role in these conditions ( $p=$ 0.0119).

Conclusions and Implications: These data suggest that EDS/HSD and autism share aspects of immune/autonomic/endocrine dysregulation, pain, and some tissue fragility, which is typically more severe inthe former. This overlap, as well as documented comorbidity, suggests some forms of autism may be hereditary connective tissue disorders (HCTD).

Key words: hereditary connective tissue disorders; immune system; collagen; dysautonomia; mast cell activation disorders

Citation: Casanova, E. L., Sharp, J. L., Edelson, S. M., Kelly, D. P., Sokhadze, E. M., Casanova, M. F. Immune, Autonomic, and Endocrine Dysregulation in Autism and Ehlers-Danlos Syndrome/Hypemobility Spectrum Disorders Versus Unaffected Controls. 2020 Jan 22; 2(2):82-95. Journal for ReAttach Therapy and Developmental Diversities. https://doi.org/10.26407/2019jitdd.1.20

Copyright C2019 Casanova, E. L., Sharp, J. L., Edelson, S. M., Kelly, D. P., Sokhadze, E. M., Casanova, M. F. This is an open-access article distributed under the terms of the Creative Commons Attribution-NonCommercial 4.0 Intemational License (CCBY-NC4.0)

Corresponding address:

Emily L. CASANOVA

Patewood Medical Campus, 200A Patewood Dr. Greenville, SC 29615

Tel: +1 (864) 454-1082

E-mail: casanove@greenvillemed.sc.edu; emily.casanova@prismahealth.org; scienceoveracuppa@gmail.com 


\section{Introduction}

At face value, Ehlers-Danlos syndrome (EDS)/hypermobility spectrum disorders (HSD) and autism appear to have little in common. Though autism can be accompanied by a variety of medical issues, it is first and foremost defined as a behavioral syndrome. In contrast, EDS/HSD is a group of hereditary connective tissue disorders (HCTD) believed to be due to a deficiency in collagen fibrillogenesis. Therefore, symptoms in these conditions stem largely from connective tissue dysplasias (joint instability, pain, skin elasticity, tissue fragility, etc.).

Early evidence suggests that autism and EDS/HSD overlap comorbidly (Casanova et al., 2018; BaezaVelasco et al., 2015). Although a number of case studies have been published since the 1980s, a more recent nationwide study from Sweden indicates that approximately $3 \%$ of individuals with EDS have an autism diagnosis (Fehlow \& Tennstedt, 1985; Sieg, 1992; Fehlow et al., 1993; Takei et al., 2011; Cederlöf et al., 2016). However, the high preponderance of women with EDS/HSD and the recognition that autism is often under-diagnosed in female demographics suggests this could be an underestimate of comorbidity (Gould \& AshtonSmith, 2011). Up-to-date prevalence estimates of hypermobileEDS (hEDS), the most common form of EDS, are also currently lacking, as are estimates on the new diagnostic entity, hypermobility spectrum disorders (HSD).

Although etiological mechanisms underlying the co-occurrence of EDS/HSD and autism are poorly understood, we know for instance that the extracellular matrix (ECM) plays foundational roles in brain development, providing scaffolds for proliferating and migrating neurons, as well as helping to maintain synaptic contacts throughout life (Mercier et al., 2002; Thomas \& Steindler, 1996; Sheen et al., 2005; Su et al., 2010). The immune system has also been implicated in autism's etiology and is a system that is significantly dysregulated in EDS/HSD and other hereditary connective tissue disorders (Seneviratne, 2017; Felgentreff et al., 2014; Patterson, 2011). In addition, autonomic disorders have been reported in both these groups and could be a cause or consequence of immune dysregulation (Sokhadze et al., 2018; Cheung \& Vadas, 2015; Czura \& Tracey, 2005; Roth et al., 2004; Bienenstock et al., 1987). For these reasons, we have elected to study self-reported immune and autonomic symptom frequency in the adult EDS/HSD and autism populations as compared to controls. We also investigate the frequency in autism of other symptoms typically associated with EDS/HSD, including items such as chronic pain and tissue fragility.

\section{Material and Methods}

\subsection{Study Population}

Approximately 99\% of respondents answered the survey on behalf of themselves, rather than as legal guardians of adult wards. Our study sample was composed of English-speaking adults aged 25 years or older $[N=702]$. (For basic demographics, see Table 1. Note that specific data on socioeconomic status and educational attainment levels were not recorded.)

\section{Table 1}

Sex, age, racial descent, and country of residence according to group. Figures presented represent diagnostically "pure" (i.e., non-mixed) clinical and control groups.

\begin{tabular}{llccc}
\hline Demographics & Male & $\begin{array}{c}\text { EDS/HSD } \\
(\mathbf{N = 2 6 8})\end{array}$ & $\begin{array}{c}\text { Autism } \\
(\mathbf{N = 1 5 2})\end{array}$ & $\begin{array}{c}\text { CON } \\
(\mathbf{N = 1 4 7 )}\end{array}$ \\
\hline Sex & $6 \%$ & $34.9 \%$ & $31.8 \%$ \\
& Female & $92.5 \%$ & $58.6 \%$ & $66.2 \%$ \\
& $\begin{array}{l}\text { Other } \\
\text { Average }\end{array}$ & $\begin{array}{c}1.5 \% \\
35.9 \pm 9.7 \\
\text { years }\end{array}$ & $\begin{array}{c}37.6 \pm 10.4 \\
\text { years }\end{array}$ & $33.0 \pm 10.2$ years \\
& & & & \\
\hline
\end{tabular}




\begin{tabular}{|c|c|c|c|c|}
\hline \multirow[t]{7}{*}{ Descent } & $\begin{array}{l}\text { Sub-saharan } \\
\text { African }\end{array}$ & $2.6 \%$ & $2 \%$ & $0.7 \%$ \\
\hline & $\begin{array}{l}\text { Middle Eastern } \\
\& \text { Northern } \\
\text { African }\end{array}$ & $1.5 \%$ & $0.7 \%$ & $2 \%$ \\
\hline & $\begin{array}{l}\text { East Asian \& } \\
\text { Native } \\
\text { American }\end{array}$ & $13.8 \%$ & $11.1 \%$ & $8.1 \%$ \\
\hline & South Asian & $1.1 \%$ & $0 \%$ & $0 \%$ \\
\hline & $\begin{array}{l}\text { Northwestern } \\
\text { European }\end{array}$ & $85.4 \%$ & $87 \%$ & $78.4 \%$ \\
\hline & $\begin{array}{l}\text { Eastern } \\
\text { European }\end{array}$ & $23.5 \%$ & $17.6 \%$ & $27 \%$ \\
\hline & $\begin{array}{l}\text { Southern } \\
\text { European }\end{array}$ & $17.5 \%$ & $8.5 \%$ & $17.6 \%$ \\
\hline \multirow[t]{12}{*}{ Country of Residence } & $\begin{array}{l}\text { Australia/New } \\
\text { Zealand }\end{array}$ & $4.9 \%$ & $8.6 \%$ & $2 \%$ \\
\hline & Bahrain & $0 \%$ & $0 \%$ & $0.7 \%$ \\
\hline & Belgium & $0.4 \%$ & $1.3 \%$ & $0 \%$ \\
\hline & Brazil & $0 \%$ & $0 \%$ & $0.7 \%$ \\
\hline & Canada & $9.7 \%$ & $5.3 \%$ & $10.1 \%$ \\
\hline & $\begin{array}{l}\text { Democratic } \\
\text { Republic of } \\
\text { Congo }\end{array}$ & $0 \%$ & $0 \%$ & $0.7 \%$ \\
\hline & Denmark & $0.7 \%$ & $1.3 \%$ & $0 \%$ \\
\hline & $\begin{array}{l}\text { Dominican } \\
\text { Republic }\end{array}$ & $0 \%$ & $0 \%$ & $0.7 \%$ \\
\hline & Finland & $0 \%$ & $0 \%$ & $0.7 \%$ \\
\hline & France & $0 \%$ & $3.3 \%$ & $0 \%$ \\
\hline & Germany & $0.4 \%$ & $0.7 \%$ & $2.7 \%$ \\
\hline & Iceland & $0 \%$ & $2 \%$ & $0 \%$ \\
\hline
\end{tabular}




\begin{tabular}{lccc}
\hline Israel & $0 \%$ & $0 \%$ & $0.7 \%$ \\
Italy & $0 \%$ & $0 \%$ & $0.7 \%$ \\
Netherlands & $0 \%$ & $2 \%$ & $0 \%$ \\
Norway & $0 \%$ & $0.7 \%$ & $0.7 \%$ \\
Poland & $0.4 \%$ & $0 \%$ & $1.4 \%$ \\
Russia & $0.4 \%$ & $0.7 \%$ & $1.4 \%$ \\
Singapore & $0.4 \%$ & $0 \%$ & $0 \%$ \\
South Africa & $0.4 \%$ & $0.7 \%$ & $0.7 \%$ \\
Spain & $0 \%$ & $0.7 \%$ & $0 \%$ \\
Sweden & $0.4 \%$ & $1.3 \%$ & $0 \%$ \\
United Kingdom & $9.3 \%$ & $25 \%$ & $11.5 \%$ \\
United States of & $71.3 \%$ & $45.4 \%$ & $61.5 \%$ \\
America & & $0.4 \%$ & $0.7 \%$ \\
\hline Uzbekistan & & $0 \%$ & \\
\hline
\end{tabular}

Our sample was divided into three major groups: 1) individuals reporting diagnosis of EDS or the nowobsolete joint hypermobility syndrome (JHS), with or without an additional diagnosis of autism $[N=$ 403]; 2) individuals reporting a diagnosis of autism but without a diagnosis of EDS/HSD [ $N=152]$; and 3) individuals reporting neitherEDS/HSD or autism (diagnosed or suspected) or with a ${ }^{\text {st }}$ degree relative with any of these diagnoses [ $N=147]$. Individuals who were under the age of 25 or who had a $1^{\text {st }}$ degree relative withEDS/HSD or autism and didn't themselves have either of these conditions were removed from the study. (Unfortunately, family members of those withEDS/HSD or autism did not form large enough subgroups to be studied individually.) In addition, individuals who suspected a diagnosis of EDS/HSD but did not report a diagnosis were also removed from the study. For most analyses, the data of individuals with EDS/HSD diagnoses who suspected they had autism but were undiagnosed were not used, with a few exceptions such as the analyses on maternal heredity and EDS/HSD within-group comparisons.
For analyses in which sex was controlled as a potential confounding variable, individuals who did not identify as either male or female were removed from the data pool.

The majority (74\%) of EDS/HSD respondents reported a diagnosis of hEDS [ $N=294]$. Meanwhile, $9 \%$ of EDS/HSD respondents reported a diagnosis of classic EDS (cEDS) [ $N=37], 3 \%$ reported a diagnosis of vascular EDS (vEDS) $[N=$ 12], and 6\% reported another form of EDS not easily categorized in this study. Nine percent of EDS/HSD respondents reported the older diagnosis of JHS, which would nowadays either be diagnosed as generalized hypermobility spectrum disorder (GHSD) or asymptomatic generalized joint hypermobility (A-GJH). In this case, however, all JHS respondents reported significant musculoskeletal pain and instability, indicating that they are symptomatic and would therefore fall under the G-HSD umbrella were they to be reassessed at present. 


\subsection{Survey}

This survey was approved by the Institutional Review Board (IRB) of the Greenville Health System (GHS) (ID: Pro00073030). It was an extension of a previous survey designed by our group, partly based off of the Vanderbilt Autonomic Dysfunction Center Medical Questionnaire and a series of surveys utilized by the Autism Research Institute (see Casanova et al., 2018; Vanderbilt Autonomic Dysfunction Center, 2018).

The survey was built on and hosted by the website, SurveyGizmo, and was advertised on a variety of websites, including Ehlers-Danlos-specific Facebook and reddit groups, Wrong Planet forums, and Survey Tandem. For websites such as reddit and Survey Tandem, requirements for posting research advertisements were followed according to the rules of each respective site (see Supplementary File 1 for survey). For forums and Facebook groups, the administrative teams of these webgroups were approached and asked for permission in order to post the study advertisement. Following administrator approval, the primary author posted the study advert.

The survey weblink (http://www.surveygizmo.com/s3/3420093/Expan ding-Our-Understanding-of-Symptoms-

Associated-with-Ehlers-Danlos-Syndromes) led to a description of the study, including potential risks/benefits and expectations, investigator contact information, and a waiver of consent. The survey was available and data was collected for six months. Survey questions covered a wide variety of medical and health issues, many of which have been referenced in the EDS-related literature as well as our own previous work (Casanova et al., 2018). Some of the major systems of interest include the immune (Fig. 1a), endocrine, and autonomic nervous systems, which have previously been implicated in both EDS/HSD and autism (Seneviratne et al., 2017; Kushki et al., 2013; De Wandele et al., 2014; Careaga et al., 2017; Ingudomnukul et al., 2007; Castori et al., 2012). In addition, we also asked about other symptoms associated withEDS/HSD, such as musculoskeletal pain and instability, dermatological issues (elasticity, scarring, wound healing), vascular complications, and other forms of chronic pain. Some psychiatric comorbidities were also covered in the survey.

\subsection{Statistical Analyses}

Group comparisons for binary outcomes were compared using logistic regression analysis. When a group proportion for a particular symptom was zero or very small, odds ratio confidence intervals including that group were unbounded (upper bound was infinity) and were not interpreted. Multiple comparisons within a particular symptom were adjusted using a false discovery rate $p$-value adjustment. For comparing symptom sums among the groups, a Kruskal-Wallis test was used. Followup analyses to compare groups pairwise were considered using the Wilcoxon Rank Sum Test. A significance level of 0.05 was used for all tests of significance.

\section{Results}

\subsection{The Immune, Endocrine, \& Autonomic Nervous Systems}

In agreement with the general literature, we found that the distributions of immune-mediated and autonomic symptoms differed across our control group by gender (women $>$ men) $[W=2826.5$ 2843, $p=0.021-0.024]$ (Oertelt, 2012; Lambrechtet al., 2010). A similar gender disparity was also present within each of our clinical groups, although the number of men within the EDS/HSD group ( $N$ $=16$ ) was comparatively small given the extreme sex-skewing of the condition [ $W=2826.5-3018, p$ $<0.001-0.016$ ] (Hamonet \& Brock, 2015). Using a series of Kruskal-Wallis rank sum tests, we found that immune-mediated and autonomic symptoms were also staggered according to group: individuals with EDS/HSD reported the most symptoms, followed by those with autism, and finally controls $\left[X^{2}=11.782-217.57, p<0.0001-0.003\right]$ (Fig. 1b,c). In contrast, endocrine-mediated symptoms primarily differed in females by group (EDS/HSD $>$ autism $>$ controls) $\left[X^{2}=55.792, p<0.0001\right]$ (Fig. 1d) but did not differ significantly in males $\left[X^{2}=\right.$ $1.6871, p=0.4302]$. This was due to the fact that female-specific endocrine disorders (e.g., endometriosis, menorrhagia) were the major drivers of group divergence in this study. (See Supplementary File1, Table 1 for full results. 
A

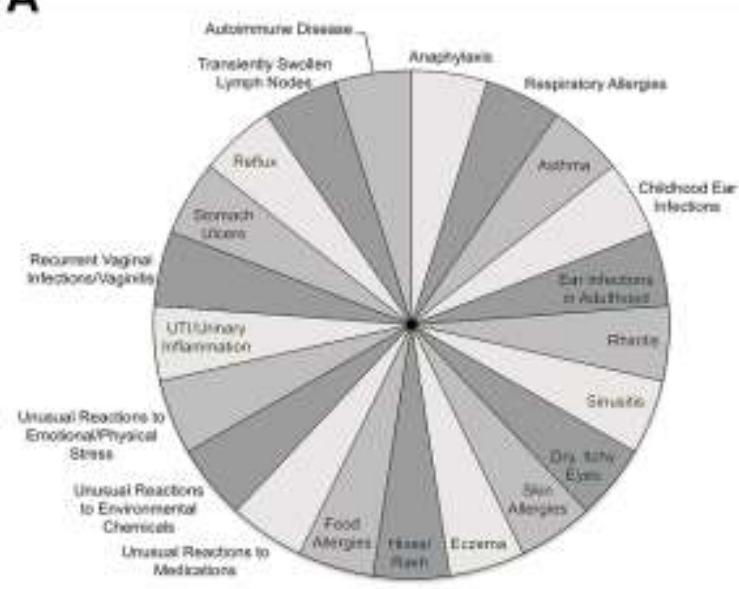

C

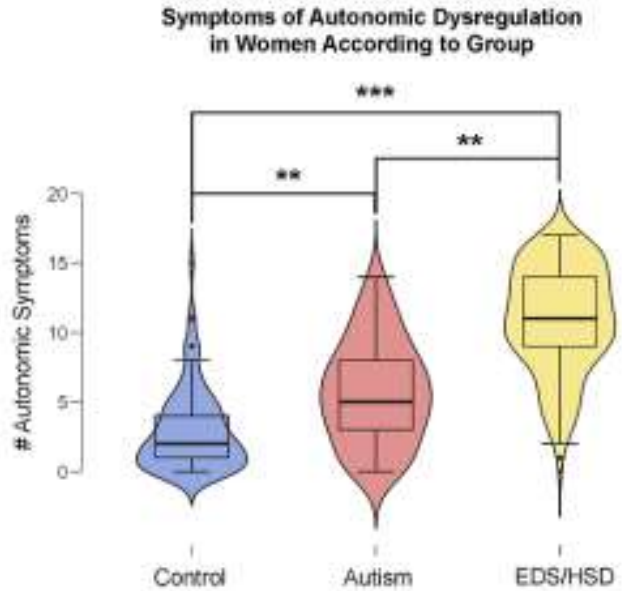

B

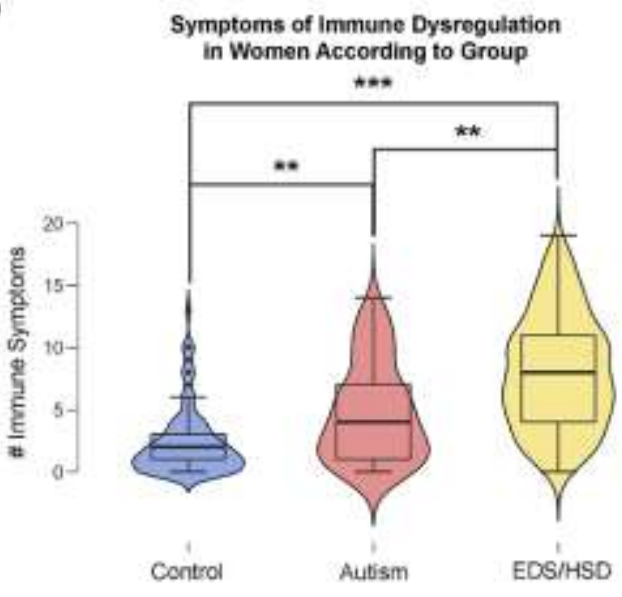

D

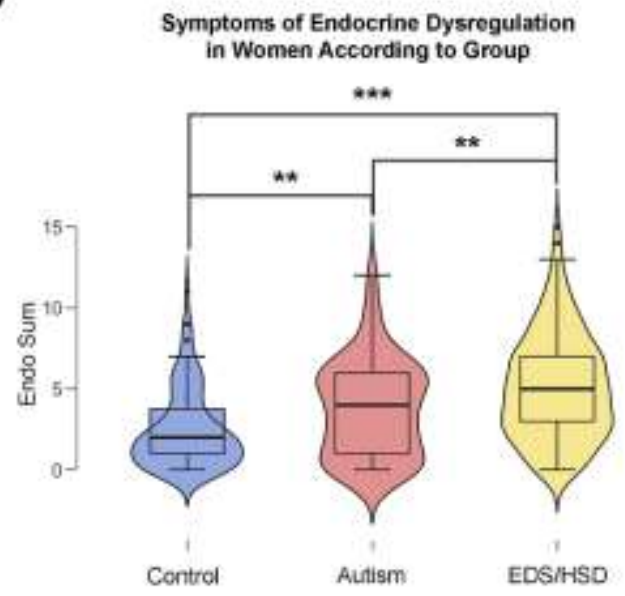

Figure 1: Immune, endocrine, and autonomic dysregulation.

(A) Pie chart listing the various immune-mediated symptoms investigated in this study. (Slices are not proportional to rate of occurrence in this study.) (B-D) Immune-, autonomic-, and endocrine-mediated symptoms in women according to group.

When we looked at EDS/HSD subtypes, we found that their immune, autonomic, and endocrine profiles were more similar than not. While we were unable to investigate all EDS subtypes due to their rarity, we were nevertheless able to compare hEDS, cEDS, vEDS, and JHS (the latter a diagnosis which many respondents retain due to the recency of nosological changes) (Castori et al., 2017). There was a significant difference in the distribution of both immune-mediated and autonomic symptoms according to EDS/HSD subtype $\left[X^{2}=13.205\right.$ 16.234, $p=0.0027-0.0103$ ], though endocrine symptoms did not appear to differ $\left[X^{2}=4.9388, p=\right.$ 0.2936]. Immunologically and autonomically, JHS is less severe than the other EDS subtypes; however, symptomologically JHS is more similar to EDS than to either the autism or control groups, suggesting a difference in severity rather than necessarily one of kind (Supplementary File 2, Table 2).

There is a small but growing literature that suggests an etiological overlap between EDS/HSD and autism (Casanova et al., 2018; Baeza-Velasco et al., 2015). While we are unable to estimate true comorbidity rates in this study due to the ways in which respondents were recruited (potential bias), we will nevertheless briefly describe ourEDS/HSD sample. Approximately $12 \%$ of EDS/HSD participants reported a dual diagnosis of autism. Meanwhile, an additional $21 \%$ of EDS/HSD respondents reported that they suspected they had autism or fell within the broader phenotype. Therefore, up to one-third of our EDS/HSD sample may have been on or near the autism spectrum. 
We also found that a large percentage of EDS/HSD mothers reported having autistic children (20\%), a figure that was almost identical to that seen in mothers with autism (19\%) (Fig. 2a). Although the log odds did not significantly differ between the two groups $\left[X^{2}=1.1322, p=0.5677\right]$, these results must be interpreted with extreme caution due to the potentially biased manner in which respondents were recruited. Interestingly, rates of autism in the offspring did not significantly differ across the different maternal EDS/HSD subgroups, which tentatively suggests that autism may be associated with various forms of EDS/HSD $\left[X^{2}=0.4807, p=\right.$ 0.4881] (Fig. 2b). Further research is desperately needed to determine both autism comorbidity and inheritance rates in these families.
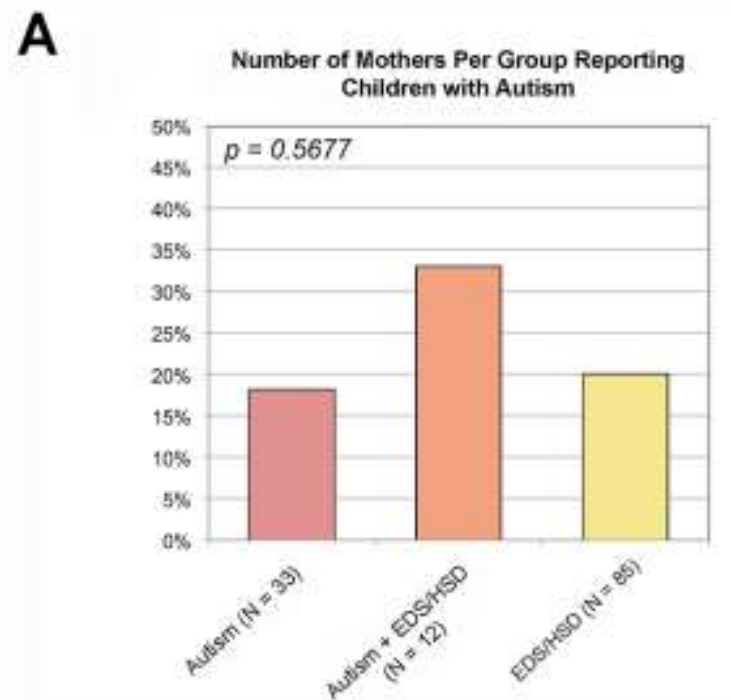

C

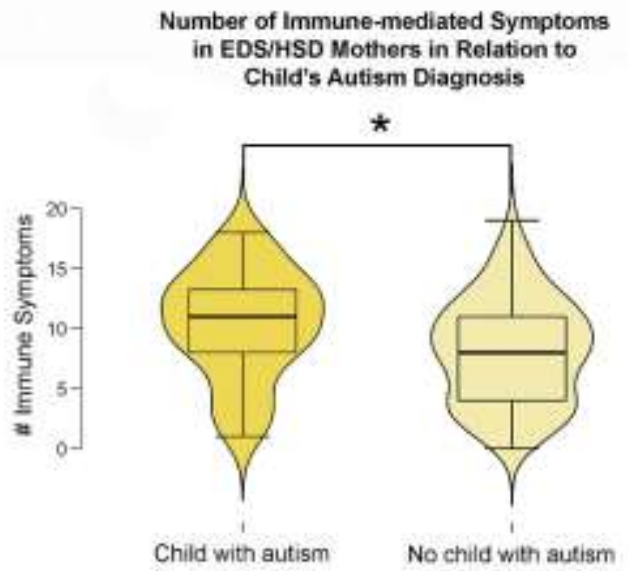

B

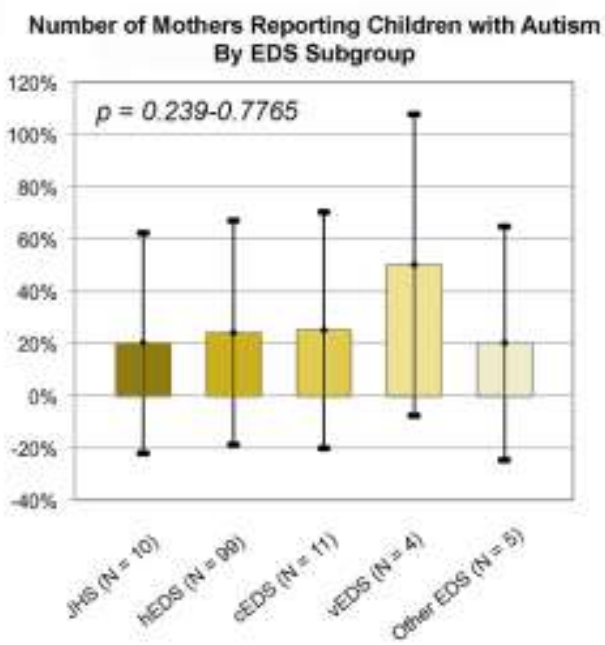

D

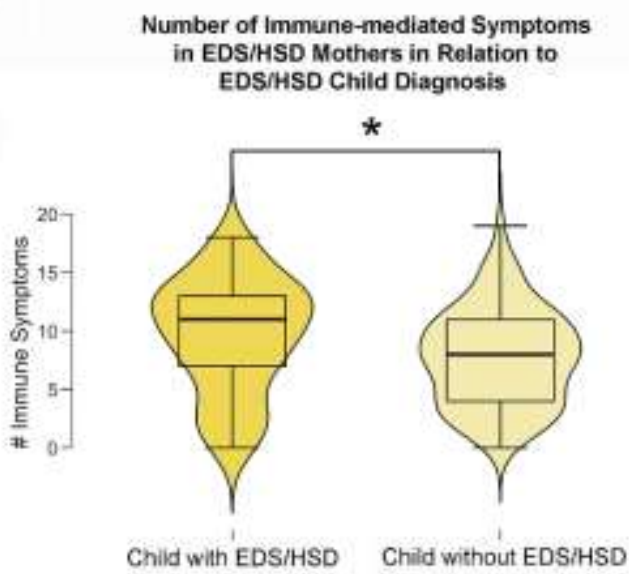

Figure 2: Autism and EDS/HSD in the Offspring

(A) Reported rates of autism diagnosis in children of mothers with clinical syndromes of interest. (B) Reported rates of EDS/HSD diagnosis in children of mothers with clinical syndromes of interest. (C) Rates of immune-mediated symptoms in mothers with EDS/HSD in relation to the child's autism diagnosis. (D) Rates of immune-mediated symptoms in mothers with EDS/HSD in relation to the child's EDS/HSD diagnosis.

More intriguingly, the distribution of immunemediated symptoms in EDS/HSD mothers who had autistic children significantly differed from those with non-autistic children, with the former reporting on average $28 \%$ more symptoms than the latter [mean $=10.4$ symptoms $(\mathrm{Sx})>8.1 \mathrm{Sx}, t=$ -
2.51, $p=0.015$ ] (Fig. 2c). Surprisingly, the distribution of immune symptoms between EDS/HSD mothers who had EDS/HSD children and those without also significantly differed, with the former reporting about $25 \%$ more symptoms than the latter $($ mean $=9.6 \mathrm{Sx}>7.7 \mathrm{Sx})[W=1496$, 
$p=0.0145]$ (Fig. 2d). However, neither of these groups experienced significantly increased autonomic or endocrine-mediated symptoms [ $W=$ 1321-1760, $\quad p=0.0945-0.2356]$ (1) (see Supplementary File 2, Fig. 1). Therefore, the
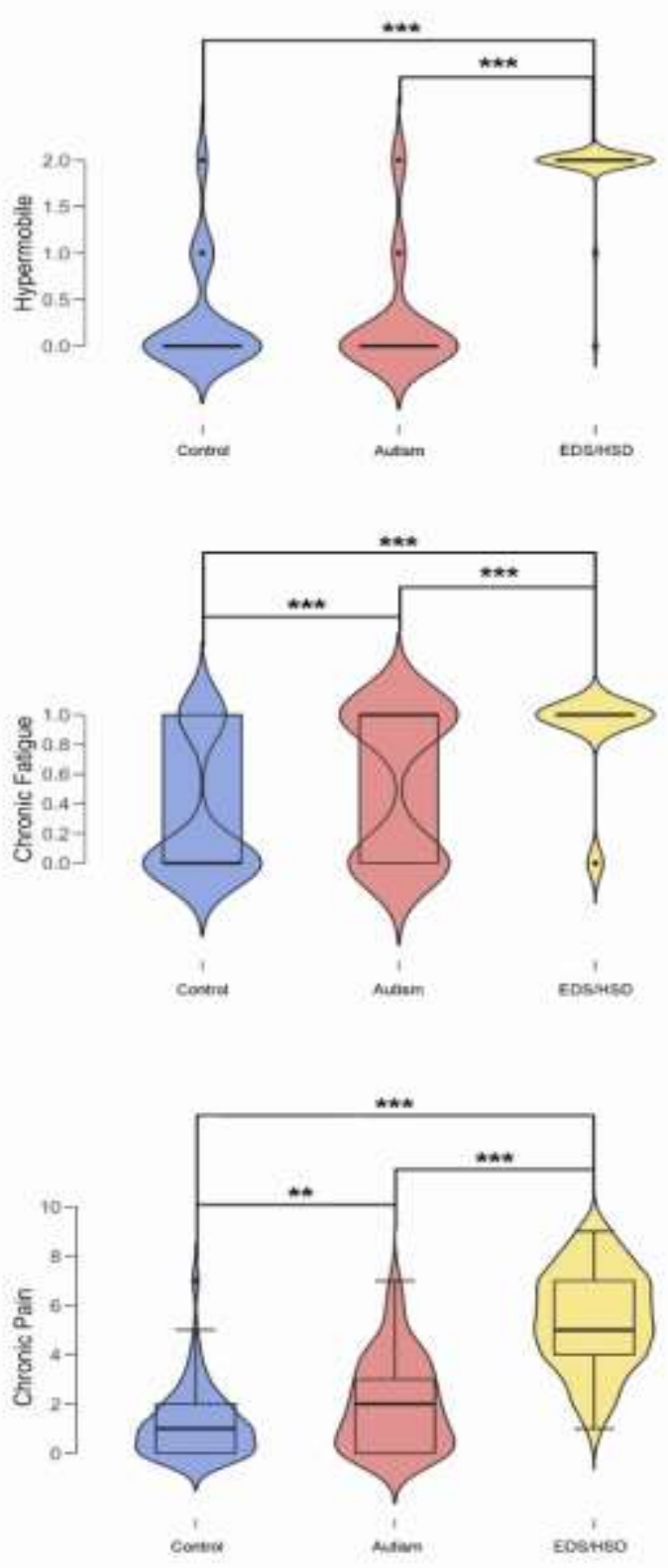

etiologies of both EDS/HSD and autism seem to share links with the maternal immune system in particular (Garay et al., 2013; McDougle, 2018). (For more results involving immune dysregulation, see Supplementary File 2, Fig. 2-3.)
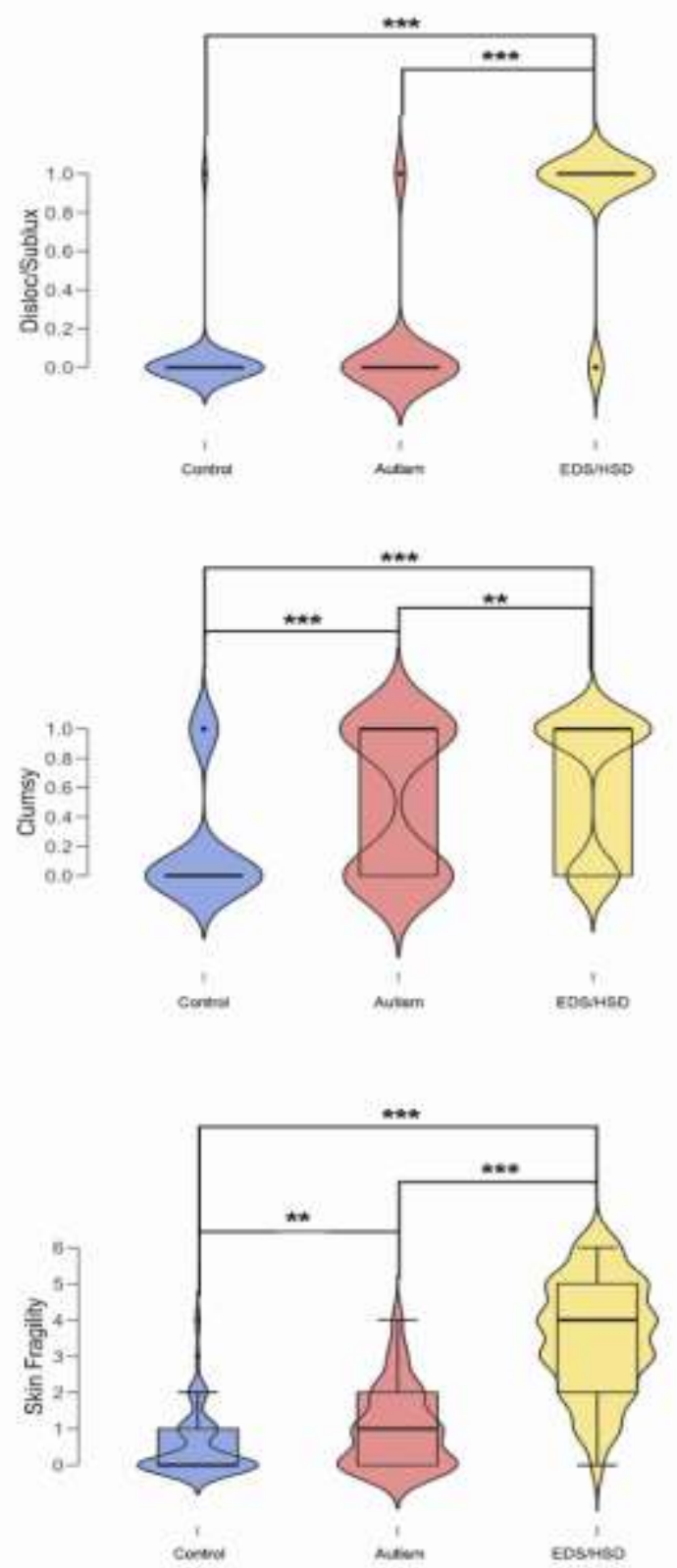

Figure 3: EDS/HSD-associated Symptoms

Reported rates of hypermobility, dislocations/subluxations, chronic fatigue, clumsiness, chronic pain, and skin fragility according to group.

\subsection{Other Ehlers-Danlos-related Symptomology}

We collected data on additional symptomology associated with EDS/HSD, in order to compare relative frequencies across groups (Table 2). (Due to small numbers within the male EDS/HSD subgroup, all results reported here concern females only unless otherwise stated.) In terms of hypermobility, joint dislocations/subluxations, skin fragility, chronic pain, general clumsiness, and chronic fatigue, as expected the EDS/HSD group 
reported significantly more symptoms compared to both the autistic and control groups [all $p>0.001$ 0.0022] (Fig. 3). The autism group likewise differed from controls in terms of clumsiness, chronic pain, chronic fatigue, and skin fragility [all $p \leq 0.002$ ], but did not differ as to hypermobility and dislocations/subluxations [all $p=0.136-0.6568$ ]
Males with autism also significantly differed from control males in the same regards [all $p=0.028$ 0.042]. These data suggest that some forms of chronic pain, tissue fragility, and fatigue may be of concern even in autism unassociated with EDS/HSD.

\section{Table 2}

EDS-associated symptom frequency by group

\begin{tabular}{|c|c|c|c|c|}
\hline & EDS/HSD & Autism & $\mathrm{CON}$ & $\begin{array}{c}\text { Respondents } \\
\text { used in } \\
\text { analysis }\end{array}$ \\
\hline Head Injury & $20 \%$ & $8 \%$ & $9 \%$ & females only \\
\hline Migraine & $80 \%$ & $52 \%$ & $42 \%$ & females only \\
\hline Non-migraine headache & $47 \%$ & $11 \%$ & $15 \%$ & females only \\
\hline Bruise Easily & $87 \%$ & $46 \%$ & $32 \%$ & females only \\
\hline Difficult-to-control bleeds & $29 \%$ & $1 \%$ & $2 \%$ & females only \\
\hline Scars easily & $70 \%$ & $27 \%$ & $14 \%$ & females only \\
\hline Cigarette paper scars & $46 \%$ & $1 \%$ & $0 \%$ & females only \\
\hline Elastic skin & $47 \%$ & $6 \%$ & $0 \%$ & females only \\
\hline Slow wound healing & $66 \%$ & $19 \%$ & $5 \%$ & females only \\
\hline Clumsy & $66 \%$ & $52 \%$ & $19 \%$ & females only \\
\hline Joint pain & $95 \%$ & $26 \%$ & $16 \%$ & females only \\
\hline Muscle pain & $82 \%$ & $21 \%$ & $7 \%$ & females only \\
\hline Arthritis & $29 \%$ & $12 \%$ & $6 \%$ & females only \\
\hline Fibromyalgia & $29 \%$ & $10 \%$ & $2 \%$ & females only \\
\hline $\begin{array}{l}\text { Temporomandibular joint } \\
(T M J) \text { pain }\end{array}$ & $64 \%$ & $24 \%$ & $9 \%$ & females only \\
\hline Neuropathy & $36 \%$ & $7 \%$ & $4 \%$ & females only \\
\hline $\begin{array}{l}\text { Joint } \\
\text { dislocations/subluxations }\end{array}$ & $89 \%$ & $8 \%$ & $3 \%$ & females only \\
\hline Foot problems & $90 \%$ & $42 \%$ & $33 \%$ & females only \\
\hline $\begin{array}{l}\text { Crooked/crowded teeth } \\
\text { (current or historicalf) }\end{array}$ & $78 \%$ & $69 \%$ & $53 \%$ & females only \\
\hline Scoliosis & $36 \%$ & $15 \%$ & $11 \%$ & females only \\
\hline Kyphosis & $13 \%$ & $2 \%$ & $2 \%$ & females only \\
\hline Missing/extra bones & $17 \%$ & $8 \%$ & $5 \%$ & females only \\
\hline Chiari malformation & $6 \%$ & $0 \%$ & $0 \%$ & females only \\
\hline Prematurity (self) & $13 \%$ & $16 \%$ & $12 \%$ & females only \\
\hline Prematurity (child) & $25 \%$ & $9 \%$ & $24 \%$ & mothers only \\
\hline Preeclampsia & $26 \%$ & $9 \%$ & $26 \%$ & mothers only \\
\hline Gestational diabetes & $11 \%$ & $6 \%$ & $18 \%$ & mothers only \\
\hline Uterine prolapse & $13 \%$ & $3 \%$ & $0 \%$ & mothers only \\
\hline Miltral valve prolapse & $14 \%$ & $3 \%$ & $2 \%$ & females only \\
\hline Venous arterial dissection & $1 \%$ & $0 \%$ & $0 \%$ & females only \\
\hline
\end{tabular}




\begin{tabular}{lcccc}
\hline Cavernous sinus fistula & $0 \%$ & $0 \%$ & $0 \%$ & females only \\
Aneurysm & $2 \%$ & $0 \%$ & $1 \%$ & females only \\
Brain hemorrhage & $0 \%$ & $1 \%$ & $0 \%$ & females only \\
Stroke & $1 \%$ & $1 \%$ & $0 \%$ & females only \\
Other vascular & $15 \%$ & $0 \%$ & $3 \%$ & females only \\
complications & & & & \\
Myopia & $61 \%$ & $62 \%$ & $45 \%$ & females only \\
Eye strain & $52 \%$ & $26 \%$ & $5 \%$ & females only \\
Retinal detachment & $3 \%$ & $1 \%$ & $0 \%$ & females only \\
Ptosis & $21 \%$ & $4 \%$ & $2 \%$ & females only \\
Blue/gray sclera & $24 \%$ & $1 \%$ & $0 \%$ & females only \\
Astigmatism & $64 \%$ & $54 \%$ & $37 \%$ & females only \\
Keratoconus & $3 \%$ & $1 \%$ & $0 \%$ & females only \\
Chronic dry eye & $36 \%$ & $9 \%$ & $10 \%$ & females only \\
Strabismus & $11 \%$ & $7 \%$ & $4 \%$ & females only \\
All cancer (self) & $5 \%$ & $4 \%$ & $2 \%$ & females only \\
Cancer under 35 & $4 \%$ & $0 \%$ & $1 \%$ & females only \\
Epilepsy (self) & $4 \%$ & $6 \%$ & $0 \%$ & females only \\
Epilepsy (relatives) & $8 \%$ & $5 \%$ & $1 \%$ & males and \\
ADHD & & & & females \\
Anxiety disorder & $20 \%$ & $19 \%$ & $7 \%$ & females only \\
Mood disorder & $42 \%$ & $42 \%$ & $26 \%$ & females only \\
PTSD & $29 \%$ & $47 \%$ & $20 \%$ & females only \\
Adverse reaction to & $13 \%$ & $8 \%$ & $3 \%$ & females only \\
vaccination & $28 \%$ & $18 \%$ & $6 \%$ & females only \\
Mild immunodeficiency & $24 \%$ & $9 \%$ & $8 \%$ & females only \\
\hline & & & &
\end{tabular}

As expected, we also found that the distribution of vascular complications, such as strokes, aneurysms, and hemorrhages, significantly differed across groups and were far more common in the EDS/HSD group (21\%), while they did not differ between autism and controls ( $2 \%$ vs. $4 \%$ ) $\left[X^{2}=\right.$ $24.809, p<0.001]$. Likewise, the log odds of head injuries and proportions of Chiari malformations differed significantly across groups, and were unusually high in the EDS/HSD group, findings which have previously been reported in the EDS literature [head injury: $X^{2}=19.086, p<0.0001$; Chiari: Fisher's Exact Test $p=0.002$ ] (Hamonet et al., 2016; Malfait et al., 2010; Castori et al., 2010) (Table 2).

\subsection{Neurodevelopmental and Psychiatric Conditions}

Both autism and EDS/HSD are sometimes associated with other neurodevelopmental and/or psychiatric conditions. When asked to report on comorbid diagnoses of attention deficit hyperactivity disorder (ADHD), anxiety disorders, mood disorders, and post traumatic stress disorder (PTSD), we found that reports significantly differed by group, although this was largely driven by clinical groups versus controls $\left[X^{2}=10.6538\right.$ $16.402, p<0.0066-0.0138]$. In fact, when analyzed individually, EDS/HSD and autism did not significantly differ from one another, although individuals with autism did report more mood disorders than those with EDS/HSD (47\% vs. 29\%). This suggests that neurodevelopmental and psychiatric comorbidities are similar across our two clinical groups and that some features of EDS/HSD may be neurodevelopmental in origin. We also found that $\log$ odds of comorbidity did not differ significantly across the EDS/HSD subgroups, indicating that they are all similarly affected and that neurodevelopmental and psychiatric conditions do not cluster within select forms of EDS $\left[X^{2}=1.0026-\right.$ 
3.017, all adjusted $p=0.8006$ ] (Bulbena-Cabré \& Bulbena, 2018).

\section{Discussion}

This study attempted to investigate a variety of health issues across EDS/HSD, autism, and controls. Much of the survey design was guided by previous EDS/HSD research (Casanova et al., 2018). Given the apparent (though still poorly delineated) comorbidity between EDS/HSD and autism, we felt it was important to determine to what extentEDS/HSD issues affect the autism spectrum. In summarizing the data presented here, those with autism (without EDS/HSD) appear to have significant issues concerning immune/autonomicl endocrine dysregulation, connective tissue (skin) durability, chronic pain, and fatigue. In addition, autistic women experience more endocrine disorders than sex-matched controls. All of these symptoms appear to be less extreme than those seen in individuals with EDS/HSD, which may share striking comorbidity with autism. In contrast, issues such as hypermobility, dislocations/subluxations, vascular complications, chiari malformation, and head injury all appear to be largely specific to the EDS/HSD diagnosis.

Autism seems to occur alongside EDS/HSD with some frequency, although we cannot estimate comorbidity rates in this study due to potential recruitment bias. There is also evidence to suggest that maternal EDS/HSD could be a risk factor for the development of autism and EDS/HSD in the offspring, although, once again, more research is needed to address this possibility. In particular, our data indicate that the maternal immune system may play a regulatory role, a finding that echoes the general autism literature (Patterson, 2011).

\subsection{Limitations}

As with all survey studies, the veracity and applicability of our data is a reflection of the reliability of reporting of our respondents. Because our findings generally agree with those previously reported throughout the EDS/HSD and autism literature, this lends support to the data and the conclusions presented here, although clearly more clinical research is needed (Seneviratne et al., 2017; Kushki et al., 2013; De Wandele et al., 2014; Careaga et al., 2017; Ingudomnukul et al., 2007).

Recent changes in hEDS nosology also make it challenging to accurately assign participants to the
EDS versus HSD subheadings as many will have received diagnoses prior to the latest diagnostic update. For this reason all respondents reporting a form of EDS, G-HSD, or JHS have been subsumed under the general "EDS/HSD" heading for most analyses. Given evidence of their relatedness both in this and previous studies, as well as the musculoskeletal impairment reported by our sample of respondents, we feel such a compilation is justified.

Another limitation of some of our EDS/HSD data involves small sample sizes. While the number of hEDS participants was substantial, the rarer forms of EDS, such as vEDS, were especially small in number and it is therefore difficult to draw conclusions about their responses, except to say that with current numbers the vEDS data do not appear to differ substantially from the other EDS/HSD subgroups. While this must be interpreted cautiously, it does suggest that people with vEDS experience many of the same secondary clinical phenotypes as the more common forms of EDS/HSD, reinforcing concepts of a common Ehlers-Danlos syndrome despite genetic heterogeneity. Further research will continue to test this possibility.

Finally, as has been mentioned previously, we cannot address comorbidity and inheritance rates between EDS/HSD and autism due to the ways in which participants were recruited. It is therefore possible and perhaps likely that individuals with comorbid EDS/HSD and autism diagnoses or EDS/HSD parents with autistic children were more drawn to participate. For these reasons we have simply described our study population qualitatively.

\section{Conclusions}

Although we cannot estimate comorbidity rates, the data presented here suggest at least a small portion of the autism spectrum may fulfill criteria for EDS/HSD. Prevalence rates of EDS are poorly researched, with current data estimating the condition affects 1:5,000 individuals. However, current clinical expertise suggests this is an underestimation and that it is far more common (EDS Society, 2018). In summary, these data suggest an intriguing possibility that some forms of autism are HCTDs. Our laboratory continues to work to address this possibility and to help improve 
the lives of those with these spectrum conditions dealing with chronic illness.

\section{Ethics Approval and Consent to Participate}

This study was carried out in accordance with the recommendations of the Institutional Review Board of the Greenville Health System (ID: Pro00073030) and was approved by said committee. All participants have signed a waiver of consent in order to participate in the study.

\section{Consent for Publication}

All participants were provided and filled out a waiver of consent prior to taking part in this online study in accordance with the Declaration of Helsinki. With this waiver, all participants have given consent for the use and publication of their data.

\section{Availability of Data and Material}

Full raw data, as well as select statistical and descriptive results, produced in this study are available on Mendeley:

https://data.mendeley.com/datasets/48tp3vrs2t/1

\section{Conflict of Interests}

The authors declare no conflict of interests.

\section{Funding}

This work was funded by the National Institutes of Health grant [R01 HD-65279].

\section{Author Contributions}

ELC conceived of the study. ELC and SME designed the survey and ELC worked to advertise the study online. JLS performed the statistical analyses. EMS provided expertise on autonomic disorders. MFC and DPK provided expertise on autism and were integral in helping to design the overall study. All authors contributed substantially to the drafts and have read and approved the final manuscript.

\section{Acknowledgments}

We would like to thank both the Ehlers-Danlos and autism spectrum online communities. Without your willingness to participate, this study would not have been possible. In addition, we would like to thank both the reddit and Survey Tandem communities, who largely participated as controls in this study. Once again, without you this work would not have been possible.

\section{References}

Baeza-Velasco, C., Pailhez, G., Bulbena, A., \& Bagdadli, A. (2015). Joint hypermobility and the heritable disorders of connective tissue: clinical and empirical evidence of links with psychiatry. General Hospital Psychiatry, $37(1)$, 24-30. https://doi.org/10.1016/j.genhospsych.2014.1 0.002

Bienenstock, J., Tomioka, M., Matsuda, H., Stead, R.H., Quinonez, G., Simon, G.T., et al. (1987). The role of mast cells in inflammatory processes: Evidence for nerve/mast cell interactions. International Archives of Allergy and Immunology, 82(3), 238-243. https://doi.org/10.1159/000234197

Bulbena-Cabré A, \& Bulbena A. (2018). Anxiety and joint hypermobility: an unexpected association. Current Psychiatry, 17, 15-21.

Careaga, M., Rogers, S., Handsen, R. L., Amaral, D. G., Van de Water, J., \& Ashwood, P. (2017). Immune endophenotypes in children with autism spectrum disorder. Biological Psychiatry, $\quad$ 81(5), $\quad$ 434-441. https://doi.org/10.1016/j.biopsych.2015.08.0 36

Casanova, E. L., Sharp, J. L., Edelson, S. M., Kelly, D. P., \& Casanova, M. F. (2018). A cohort study comparing women with autism spectrum disorder with and without generalized joint hypermobility. Behavioral Sciences (Basel, Switzerland), 8(3), 35. https://doi.org/10.3390/bs8030035

Castori, M., Camerota, F., Celletti, C., Danese, C., Santilli, V., Saraceni, V. M., et al. (2010). Natural history and manifestations of the hypermobility type Ehlers-Danlos syndrome: a pilot study on 21 patients. American Journal of Medical Genetics A, 152A(3), 556-564. https://doi.org/10.1002/ajmg.a.33231

Castori, M., Morlino, S., Dordoni, C., Celletti, C., Camerota, F., Ritelli, M., et al. (2012). Gynecologic and obstetric implications of the joint hypermobility syndrome (a.k.a. EhlersDanlos syndrome hypermobility type) in 82 Italian patients. American Journal of Medical Genetics $\quad$ A, 158A(9), 2176-2182. https://doi.org/10.1002/ajmg.a.35506

Cederlöf, M., Larsson, H., Lichtenstein, P., Almqvist, C., Serlachius, E., \& Ludvigsson, J. F. (2016). Nationwide population-based cohort study of psychiatric disorders in individuals with 
Ehlers-Danlos syndrome or hypermobility syndrome and their siblings. BMC Psychiatry, 16, 207. https://doi.org/10.1186/s12888-0160922-6

Cheung, I., \& Vadas, P. (2015). A new disease cluster: Mast cell activation syndrome, postural orthostatic tachycardia syndrome, and Ehlers-Danlos syndrome. Journal of Allergy and Clinical Immunology, 135(2), AB65. https://doi.org/10.1016/j.jaci.2014.12.1146

Czura, C. J., \& Tracey, K. J. (2005). Autonomic neural regulation of immunity. Journal of Internal Medicine, 257(2), 156-166. https://doi.org/10.1111/j13652796.2004.01442.x

De Wandele, I., Rombaut, L., Leybaert, L., Van de Borne, P., De Backer, T., Malfait, F., et al. (2014). Dysautonomia and its underlying mechanisms in the hypermobility type of Ehlers-Danlos syndrome. Seminars in Arthritis and Rheumatism, 44(1), 93-100. https://doi.org/10.1016/j.semarthrit.2013.12.0 06

Ehlers-Danlos Society, The. What Are the EhlersDanlos Syndromes? Accessed on 7/11/2018 from: https://www.ehlers-danlos.com/whatis-eds/

Fehlow, P., \& Tennstedt, A. (1985). Concomitant neuropsychiatric symptoms in a case of Ehlers-Danlos syndrome. Psychiatrie Neurologie und Medizinische Psychologie (Leipz), 37(4), 215-220.

Fehlow, P., Bernstein, K., Tennstedt, A., \& Walther, F. (1993). Early infantile autism and excessive aerophagy with symptomatic megacolon and ileus in a case of Ehlers-Danlos syndrome. Padiatrie und Grenzgebiete, 31(4), 259-267.

Felgentreff, K., Siepe, M., Kotthoff, S., von Kodolitsch, Y., Schachtrup, K., Notarangelo, L. D., et al. (2014). Severe eczema and hyperIgE in Loeys-Dietz syndrome - contribution to new findings of immune dysregulation in connective tissue disorders. Clinical Immunology, 150(1), 43-50. https://doi.org/10.1016/j.clim.2013.11.008

Garay, P. A., Hsiao, E. Y., Patterson, P. H., \& McAllister, A. K. (2013). Maternal immune activation causes age- and region-specific changes in brain cytokines in offspring throughout development. Brain, Behavior, and Immunity, 31, 54-68. https://doi.org/10.1016.j.bbi.2012.07.008

Gould, J., \& Ashton-Smith, J. (2011). Missed diagnosis or misdiagnosis? Girls and women on the autism spectrum. Good Autism Practice (GAP), 12(1), 34-41. https://doi.org/10.1177/1039856214568214

Hamonet, C., \& Brock, I. (2015). Joint mobility and Ehlers-Danlos syndrome (EDS), new data based on 232 cases. Journal of Arthritis, $4(148), \quad 2 . \quad$ https://doi.org/10.4172/21677921.1000148

Hamonet, C., Frédy, D., Lefêvre, J. H., BourgeoisGironda, S., \& Zeitoun, J. D. (2016). Brain injury unmasking Ehlers-Danlos syndromes after trauma: the fiber print. Orphanet Journal of Rare Disorders, 11, 45. https://doi.org/10.1186/s13023-016-0428-9

Ingudomnukul, E., Baron-Cohen, S., Wheelwright, S., \& Knickmeyer, R. (2007). Elevated rates of testosterone-related disorders in women with autism spectrum conditions. Hormones and Behavior, 51(5), 597-604. https://doi.org/10.1016/j.yhbeh.2007.02.001

Kushki, A., Drumm, E., Pla Mobarak, M., Tanel, N., Dupuis, A., Chau, T., et al. (2013). Investigating the autonomic nervous system response to anxiety in children with autism spectrum disorders. PLoS One, 8(4), e59730. https://doi.org/10.1371/journal.pone.0059730

Malfait, F., Wenstrup, R. J., \& De Paepe, A. (2010). Clinical and genetic aspects of Ehlers-Danlos syndrome, classic type. Genetics in Medicine, 12(10), 597.

McDougle, C. J. (2018). Another step toward defining an immune-mediated subtype of autism spectrum disorder. JAMA Network Open, l(2), e180280. https://doi.org/10.1097/GIM.0b013e3181eed 412

Mercier, F., Kitasako, J. T., \& Hatton, G. I. (2002). Anatomy of the brain neurogenic zones revisited: Fractones and the fibroblast/macrophage network. The Journal of Comparative Neurology, 451(2), 170-188. https://doi.org/10.1002/cne.10342

Patterson PH (2011) Maternal infection and immune involvement in autism. Trends in Molecular Medicine, 17(7), 389-394. https://doi.org/10.1016/j.molmed.2011.03.00 1 
Roth, J., Harré, E.-M., Rummel, C., Gerstberger, R., $\&$ Hubschle, T. (2004). Signaling the brain in systemic inflammation: Role of sensory circumventricular organs. Frontiers in Bioscience, 290-300. https://doi.org/10.2741/1241

Seneviratne, S. L., Maitland, A., \& Afrin, L. (2017). Mast cell disorders in Ehlers-Danlos syndrome. The American Journal of Medical Genetics: Seminars in Medical Genetics C, 175(1), 226-236. https://doi.org/10.1002/ajmg.c.31555

Sheen, V. L., Jansen, A., Chen, M. H., Parrini, E., Morgan, T., Ravenscroft, R., et al. (2005). Filamin A mutations cause periventricular heterotopia with Ehlers-Danlos syndrome. Neurology, $\quad$ 64(2), 254-262. https://doi.org/10.1212/01.WNL.000014951 2.79621.DF

Sieg, K. G. (1992). Autism and Ehlers-Danlos syndrome. Journal of the American Academy of Child and Adolescent Psychiatry, 31, 173.

Sokhadze, E. M., Casanova, M. F., Casanova, E. L., Klusek, J., \& Roberts, J. (2018). Autonomic nervous system dysfunction in children with autism spectrum disorder. (Sokhadze, E. M., \& M. F. Casanova, Eds.) In: Neuromodulation, Neurofeedback and Sensory Integration Approaches for Research and Treatment. FNNR: Murfreesboro, TN, pp. 169-206.
Su, J., Gorse, K., Ramirez, F., \& Fox, M. A. (2010). Collagen XIX is expressed by interneurons and contributes to the formation of hippocampal synapses. The Journal of Comparative Neurology, 518(2), 229-253. https://doi.org/10.1002/cne.22228

Takei, A., Mera, K., Sato, Y., \& Haraoka, Y. (2011). High-functioning autistic disorder with Ehlers-Danlos syndrome. Psychiatry and Clinical Neurosciences, 65(6), 605-606. https://doi.org/10.1111/j.14401819.2011.02262.x

Thomas, L. B., Gates, M. A., \& Steindler, D. A. (1996). Young neurons from the adult subependymal zone proliferate and migrate along an astrocyte, extracellular matrix-rich pathway. Glia, 17(1), 1-14. https://doi.org/10.1002/(SICI)10981136(199605)17:1<1::AIDGLIA1>3.0.CO;2-7.

Vanderbilt Autonomic Dysfunction Center. Medical Questionnaire. Accessed on 7/6/2018 from: http://prd-medwebcdn.s3.amazonaws.com/documents/adc/files/ New\%20Autonomic\%20Questionnaire_Jun e2016\%20per\%20Dr_\%20Biaggioni.pdf 